Supplement of Atmos. Meas. Tech., 14, 2237-2260, 2021

https://doi.org/10.5194/amt-14-2237-2021-supplement

(C) Author(s) 2021. CC BY 4.0 License.

(c) (i)

Atmospheric
Measurement
Techniques

Supplement of

\title{
Aerosol pH indicator and organosulfate detectability from aerosol mass spectrometry measurements
}

Melinda K. Schueneman et al.

Correspondence to: Jose L. Jimenez (jose.jimenez@colorado.edu)

The copyright of individual parts of the supplement might differ from the article licence. 


\section{S1 Analysis of possible impact of amines during ATom}

If amines were present in sufficient concentrations, they could affect the thermodynamic calculations by providing another base to neutralize sulfuric acid. We looked at $m / z 30,44,58$, and 86 , where amines tend to produce distinctive peaks in the AMS, and examined the high resolution spectra for different flights during ATom-1 and ATom-2 (Fig. S5). The objectives were to a) evaluate whether any amine signal could be detected above background and b) if amines were detectable, to quantify their fractional contribution to the aerosol.

We observe in Fig. S5 that amines can be fit above the background during the entirety of one research flight in ATom-1 (within regime I) (here we show the fit for one amine ion, $\mathrm{C}_{2} \mathrm{H}_{6} \mathrm{~N}^{+}$) but are much smaller than $\mathrm{NH}_{4}^{+}$(see main text). Thus, we can assume amines are a negligible base for the regions where we use ammonium balance and/or $\mathrm{H}_{\mathrm{y}} \mathrm{SO}_{\mathrm{x}}{ }^{+} / \mathrm{SO}_{\mathrm{x}}{ }^{+}$to estimate aerosol acidity.

\section{S2 Quantification of organosulfates from PALMS aerosol measurements}

We also compared total sulfate to OS species glycolic acid sulfate (GAS) and IEPOX Sulfate measured by PALMS (Froyd et al., 2019) for ATom-1, shown in Fig. S6.

\section{S3 Application of the Song et al. method}

3 The Song (2019) method for estimating $\mathrm{OS}_{\mathrm{f}}$ was applied to the ATom and KORUS-AQ campaigns where data was in Regime II (calculated $\mathrm{pH}>0, \mathrm{AN}_{\mathrm{f}}<0.3$ ) in Fig. S9 and the entire ATom and KORUS-AQ campaigns, shown in Fig. S10. Results change substantially based on what type of sulfate standard was used to calculate the contribution of OS to total sulfate. When 
37 we use ambient data collected from "clean" and "dry" periods (defined in this work as RH <

$3830 \%$ and pressure altitude $>1200 \mathrm{~m}$ ) with the assumption that they mainly contain AS, the

39 average $\%$ OS in the BL is centered around $0 \%$, but fluctuates within $\pm 30 \%$. In the FT the

40 distribution narrows for all campaigns, and is centered around a few percent OS. When pure AS

41 standards were used, the estimated percent OS varied widely, from $-100 \%$ to $+50 \%$. 
42 Tables:

\begin{tabular}{|l|l|l|l|}
\hline Campaign & $\mathrm{AN}_{\mathrm{f}}$ & $\mathrm{OA}_{\mathrm{f}}$ & Avg. calculated $\mathrm{pH}$ \\
\hline $\mathrm{DC} 3$ & 0.04 & 0.6 & 0.8 \\
\hline $\mathrm{SEAC}^{4} \mathrm{RS}$ & 0.02 & 0.6 & -0.2 \\
\hline WINTER & 0.3 & 0.3 & 1 \\
\hline KORUS-AQ & 0.2 & 0.4 & 2 \\
\hline ATom-1 & 0.01 & 0.5 & -0.7 \\
\hline ATom-2 & 0.01 & 0.2 & -0.5 \\
\hline
\end{tabular}

43 Table S1. Average $A N_{f}, O A_{f}$, and calculated $p H$ for six campaigns (those shown in Fig. 1D), and 44 DC3 
45 Figures:

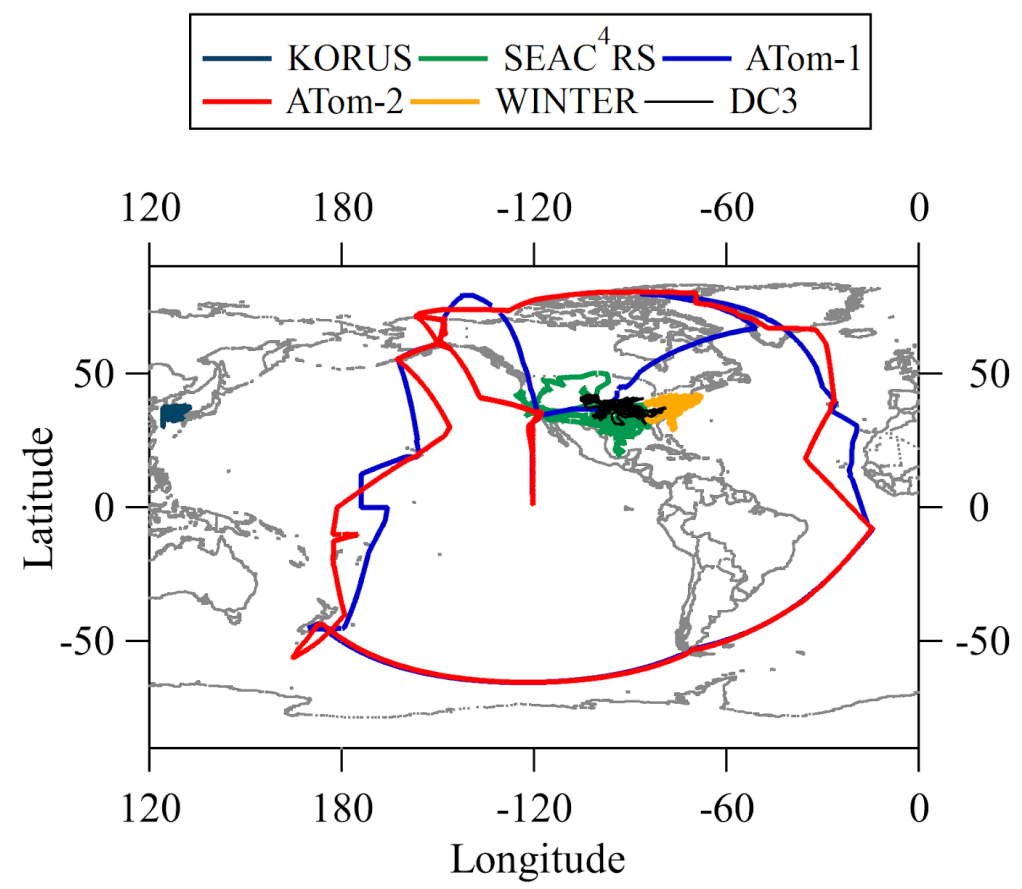

46 Fig. S1. Flight paths for the ATom-1, ATom-2, KORUS-AQ, SEAC ${ }^{4} R S, D C 3$, and WINTER 47 aircraft campaigns used in this paper. 

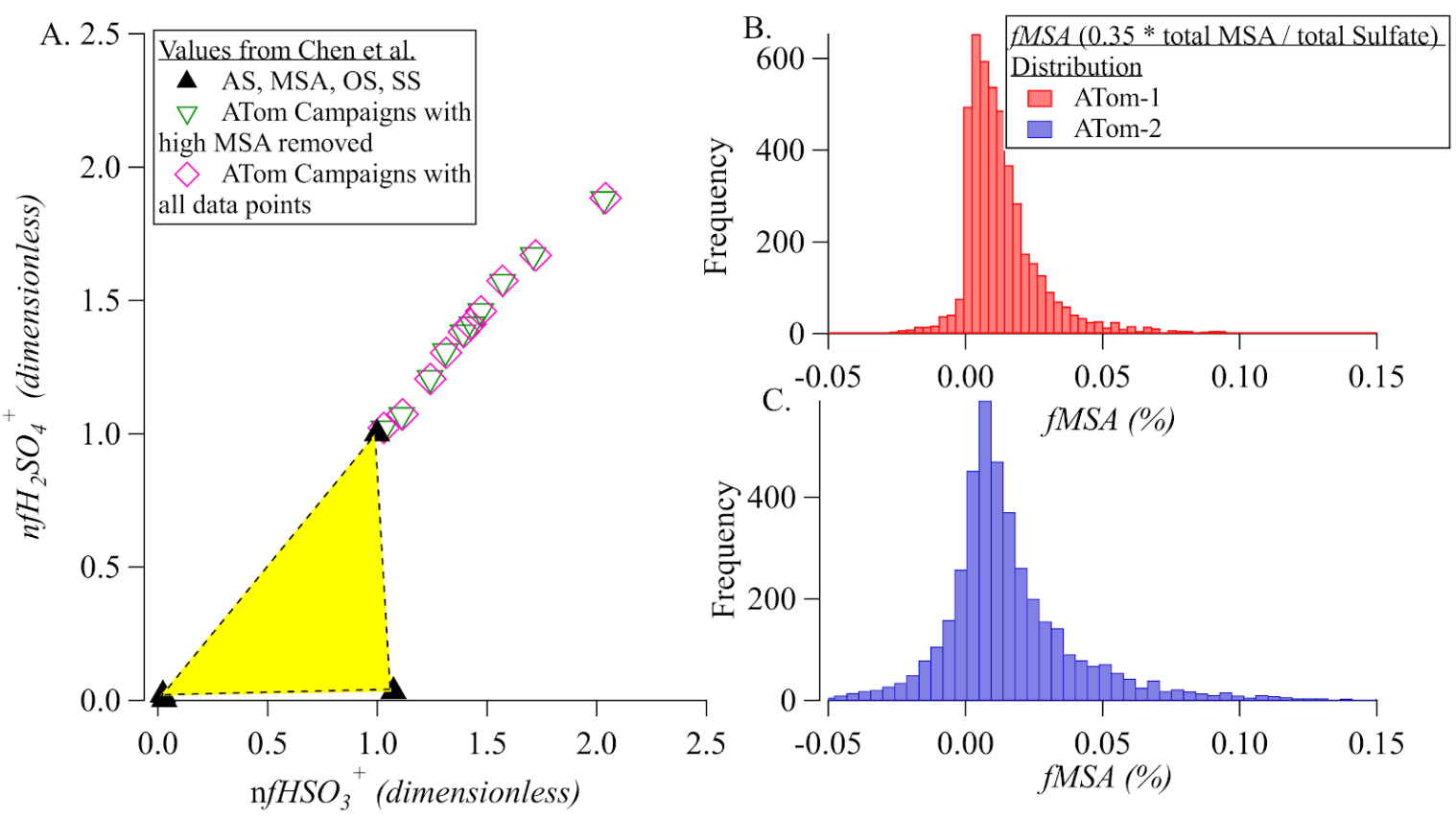

48 Fig. S2. (Left) Chen diagram for the ATom campaigns with and without the periods of higher

49 MSA concentrations (defined as fMSA >0.1 and total sulfate > 0.1). (Right) Histograms of fMSA 50 for ATom-1 and ATom-2. 


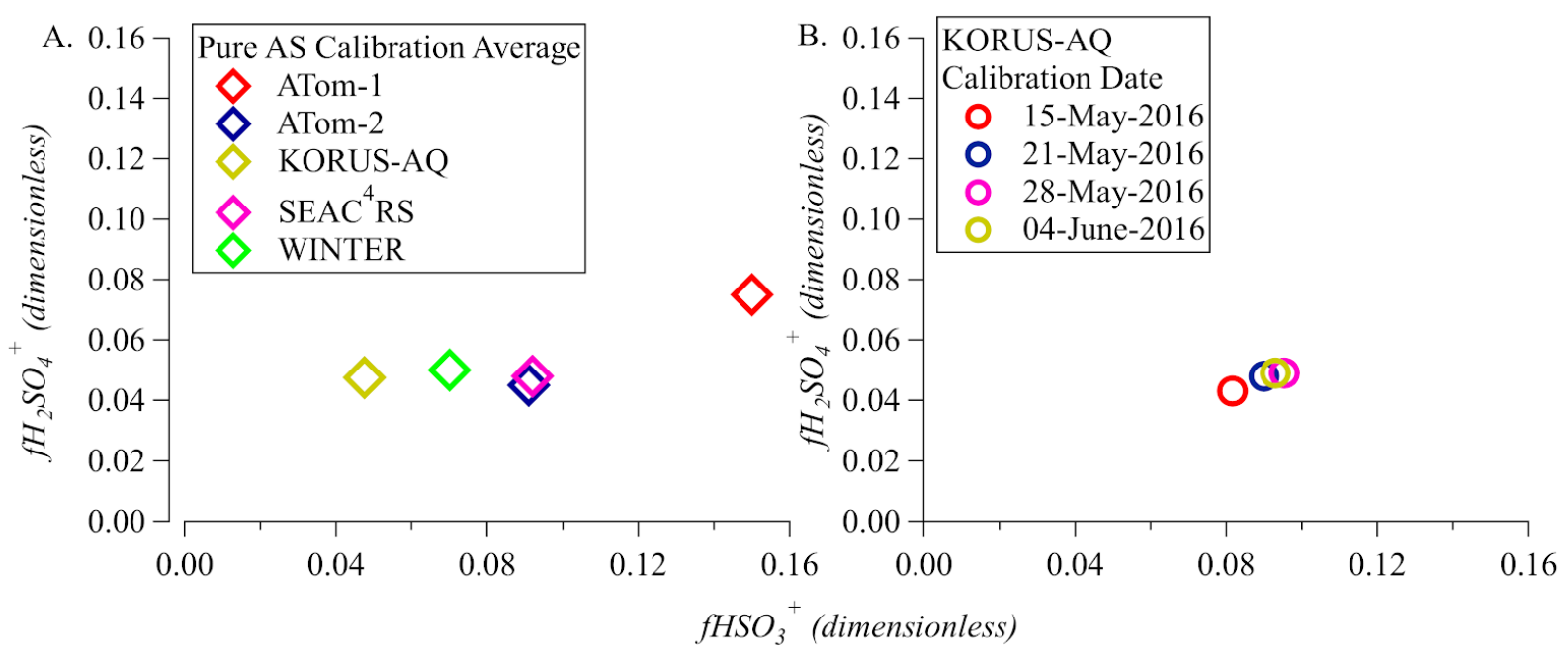

51 Fig. S3. (A) Variation of the sulfate fragment indicators for pure AS calibration averages for full 52 campaigns. The variability was caused by changes in instrument components (e.g. filaments) and 53 tuning. (B) Same for individual calibrations during KORUS-AQ, variability caused mainly by 54 filament aging. 

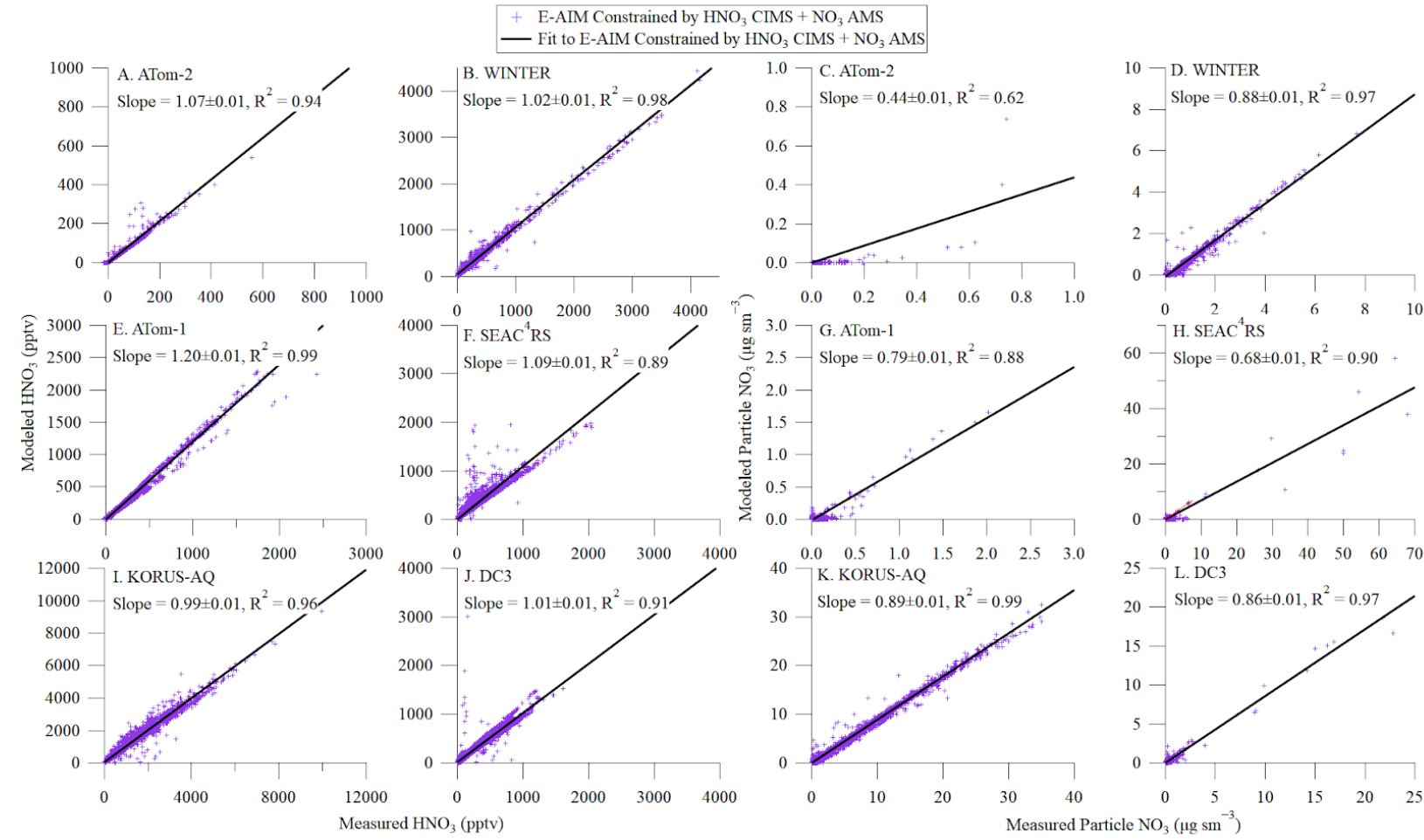

H. SEAC RS
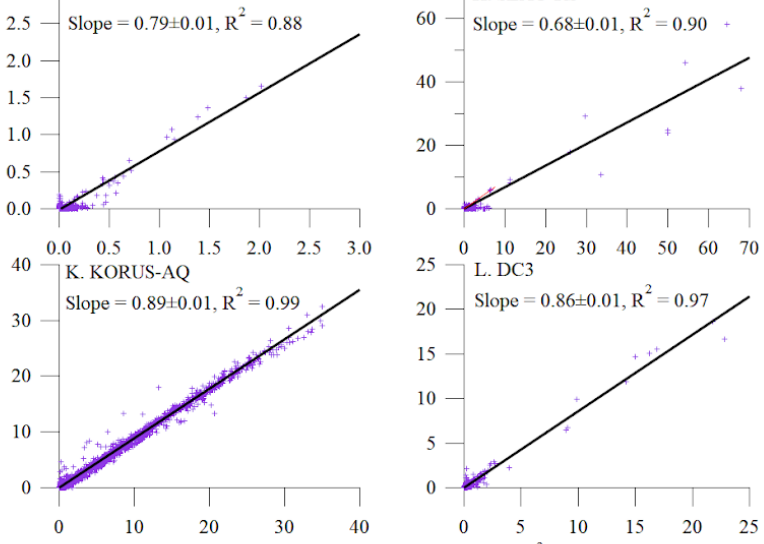
25 L. DC3

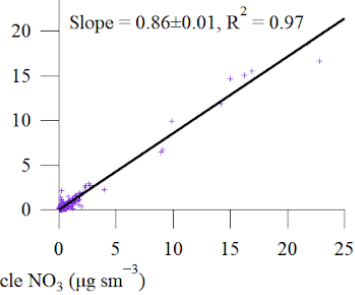

55 Fig. S4. (Left two columns) comparison of E-AIM model results to measured $\mathrm{HNO}_{3}(\mathrm{~g})$ for six 56 campaigns. (Right two columns) comparison of the measured particle inorganic nitrate 57 concentrations against the E-AIM model predictions for the same campaigns. 


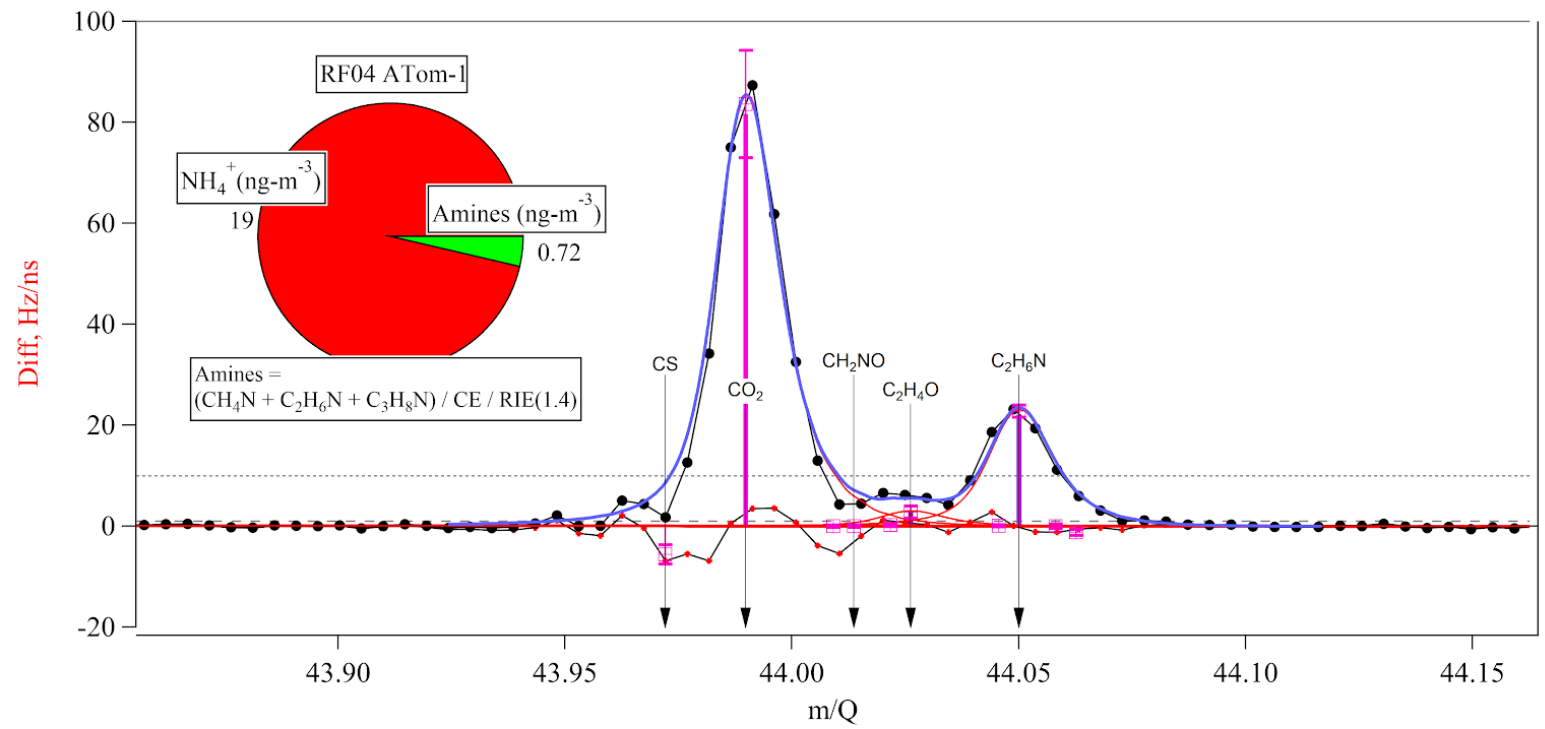

58 Fig. S5. Inset: Quantification of amines (green) in the ATom-1 flight RF104 compared to 59 ammonium (red). Main plot: high-resolution fit of the amine ion at $\mathrm{m} / \mathrm{z} 44$ in the ToF-AMS 60 analysis software 


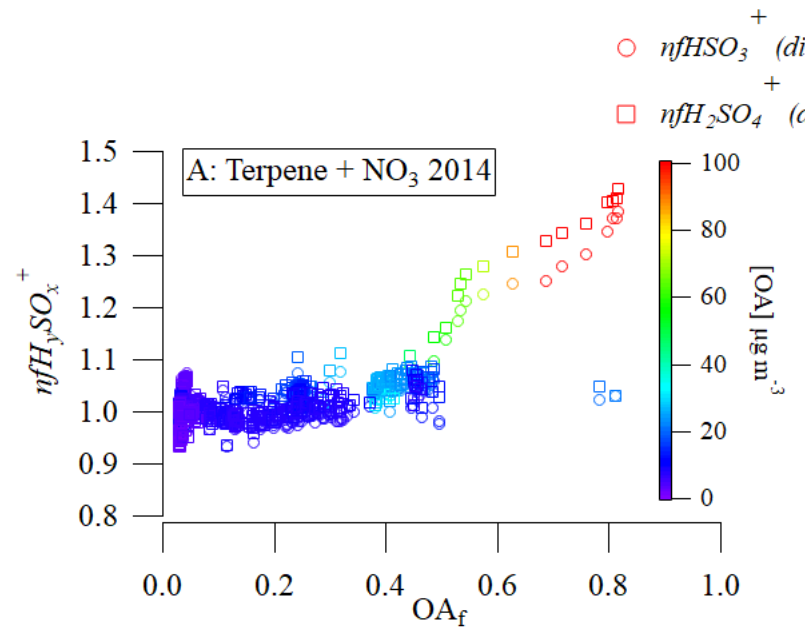

(dimensionless)
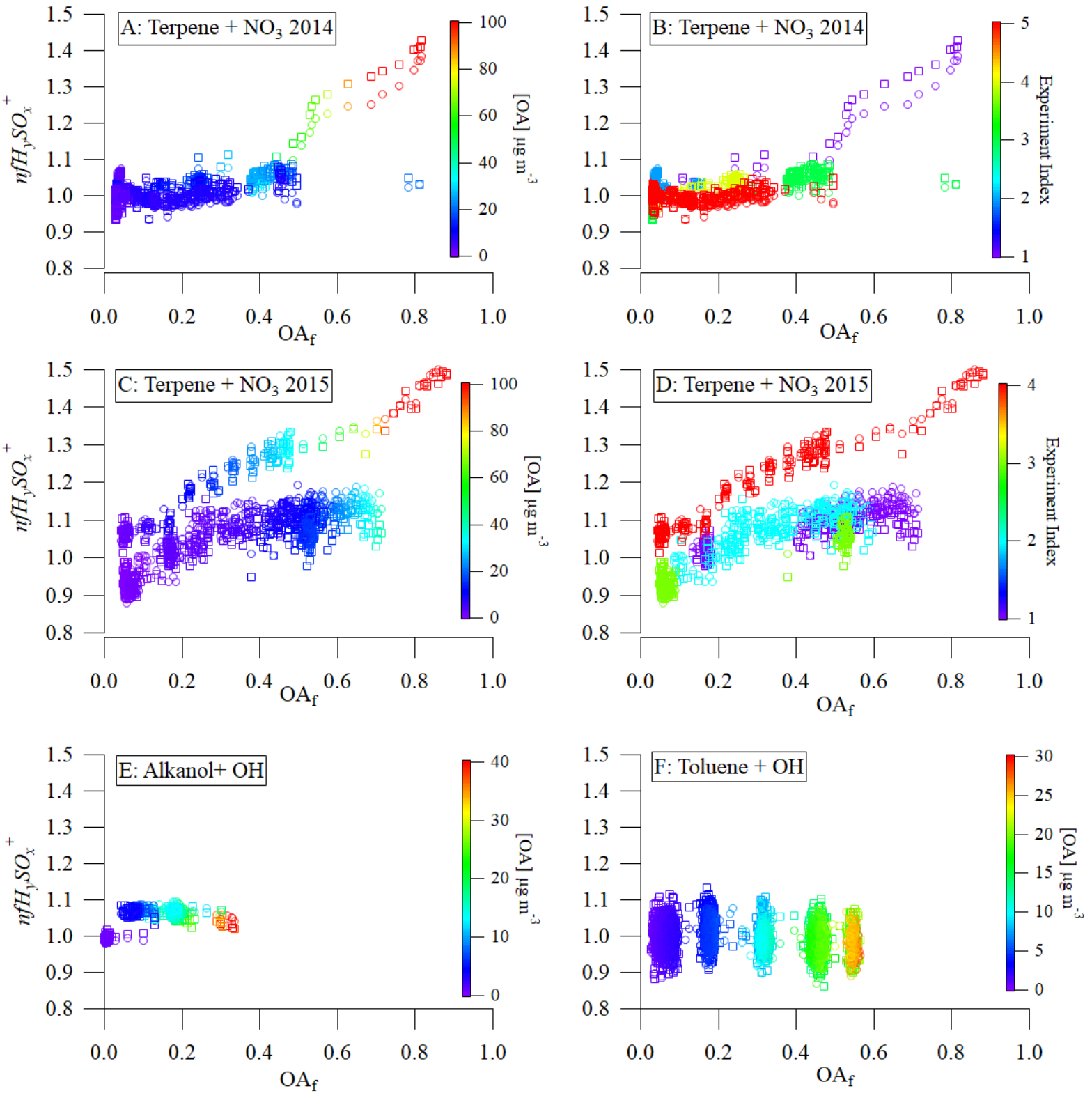

61 Fig. S6. $\mathrm{fH}_{y} \mathrm{SO}_{x}{ }^{+}$ions vs. $\mathrm{OA}_{f}$ colored by total $\mathrm{OA}$ concentration (left and bottom right) and top

62 right colored by experiment index. All data are from chamber experiments where SOA was

63 formed on ammonium sulfate seed aerosol from $(A, B, C, D)$ nitrate radical reaction with

64 monoterpenes (where 2014, 2015 represent different series of experiments done in different years

65 and different instruments), and photooxidation of $(E)$ alkanols and $(F)$ toluene. The maximum

$66[\mathrm{OA}]$ concentrations observed in (A) and (C) are 204 and $206 \mu \mathrm{g} \mathrm{m}^{-3}$, respectively. The $\mathrm{fH}_{y} \mathrm{SO}_{x}^{+}$

67 ratios have been normalized to the average ratios for the ammonium sulfate seed for each

68 experimental dataset. 

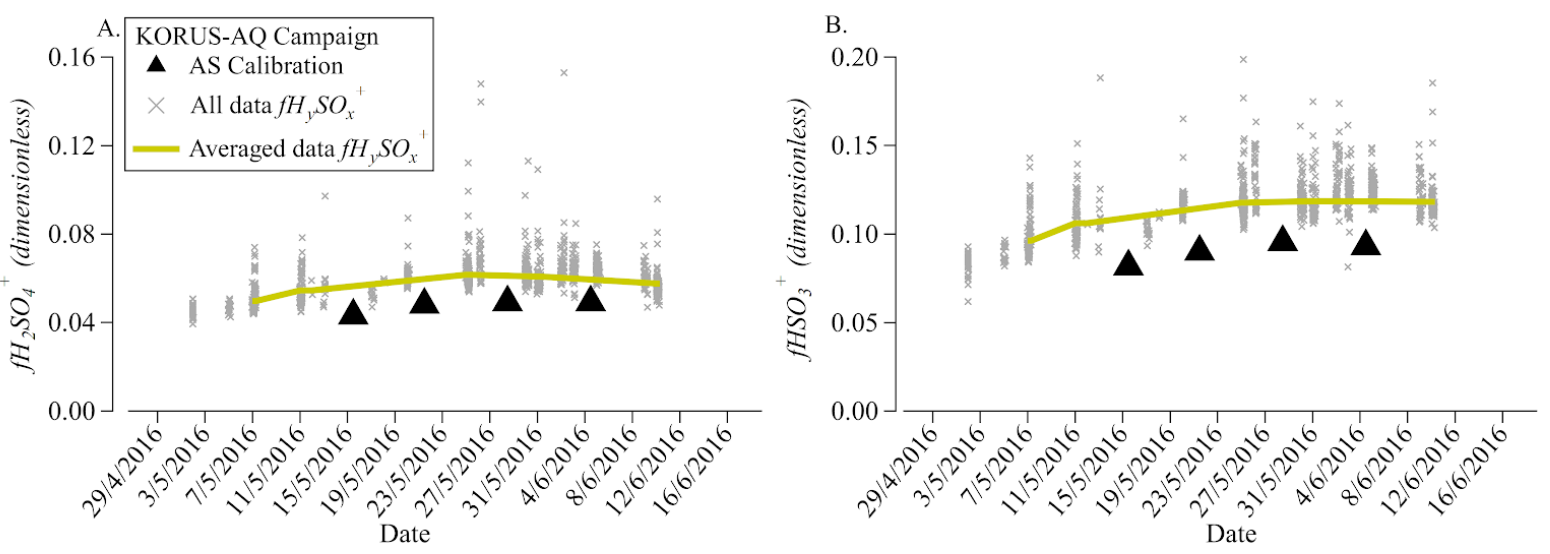

69 Fig. S7. $\mathrm{fH}_{y} \mathrm{SO}_{x}{ }^{+}$ions (not normalized) vs. time for AS calibrations and ambient sampling for the $70 \mathrm{KORUS}$-AQ campaign. (A) shows $\mathrm{fH}_{2} \mathrm{SO}_{4}^{+}$and (B) shows $\mathrm{fHSO}_{3}^{+}$. The yellow line shows

71 smoothed, average data for the campaign, and the grey points show the non-averaged ambient 72 data. Black triangles show the average $\mathrm{fH}_{y} \mathrm{SO}_{x}^{+}$values for four pure AS calibrations done during 73 KORUS-AQ. 


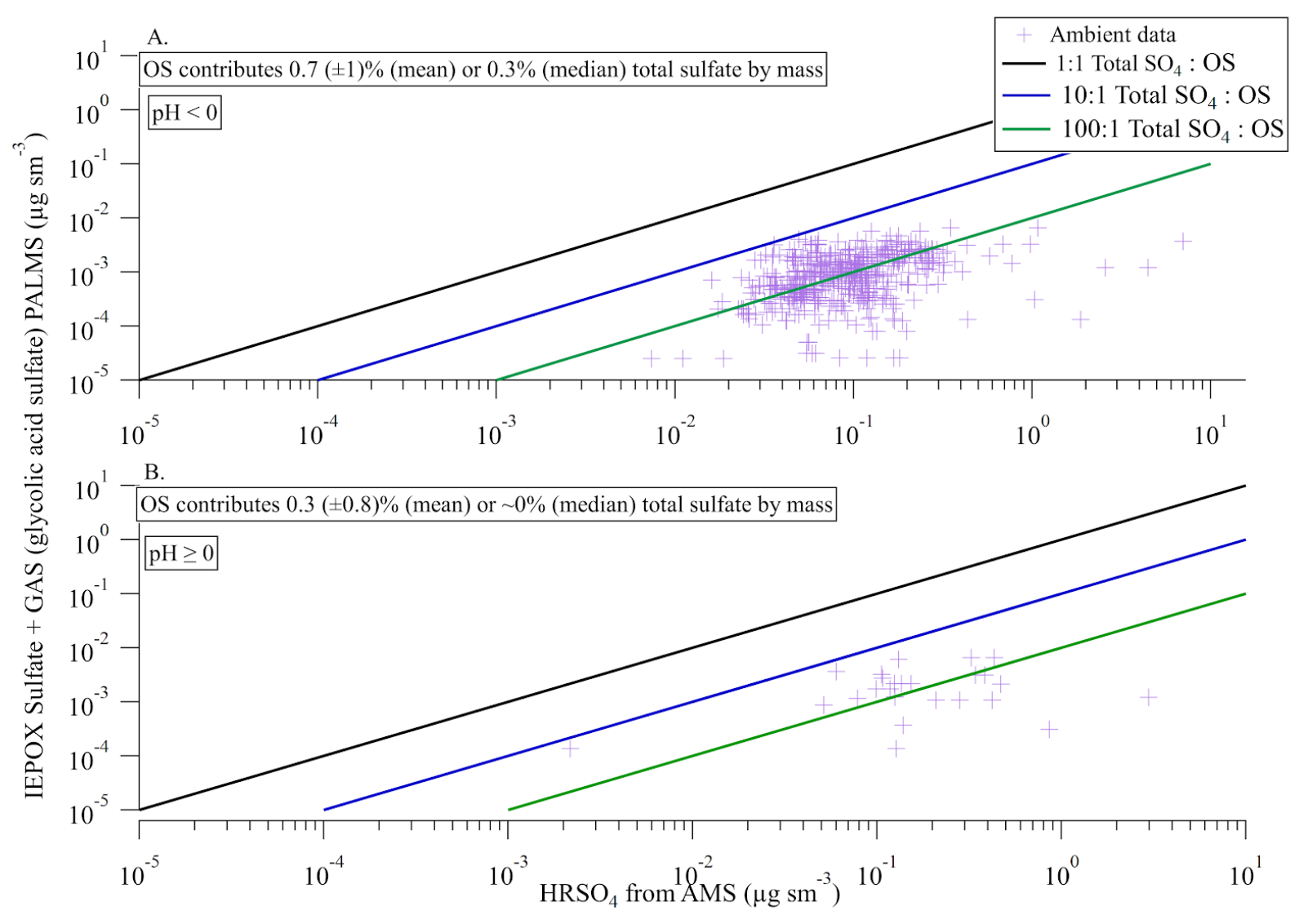

74 Fig. S8. Concentration of OS measured by PALMS (only the sulfate moiety) during ATom-1 75 against total sulfate measured by the AMS during ATom-1. The PALMS OS is calculated by 76 summing the concentrations (of the sulfate moieties only) for the IEPOX OS and glycolic acid 77 sulfate mass fractions, and multiplying by total mass from the AMS $\left(\mu \mathrm{g} \mathrm{m}^{-3}\right)$ for calculated $\mathrm{pH}>$ 780 (bottom) and calculated $p H<0$ (top). 

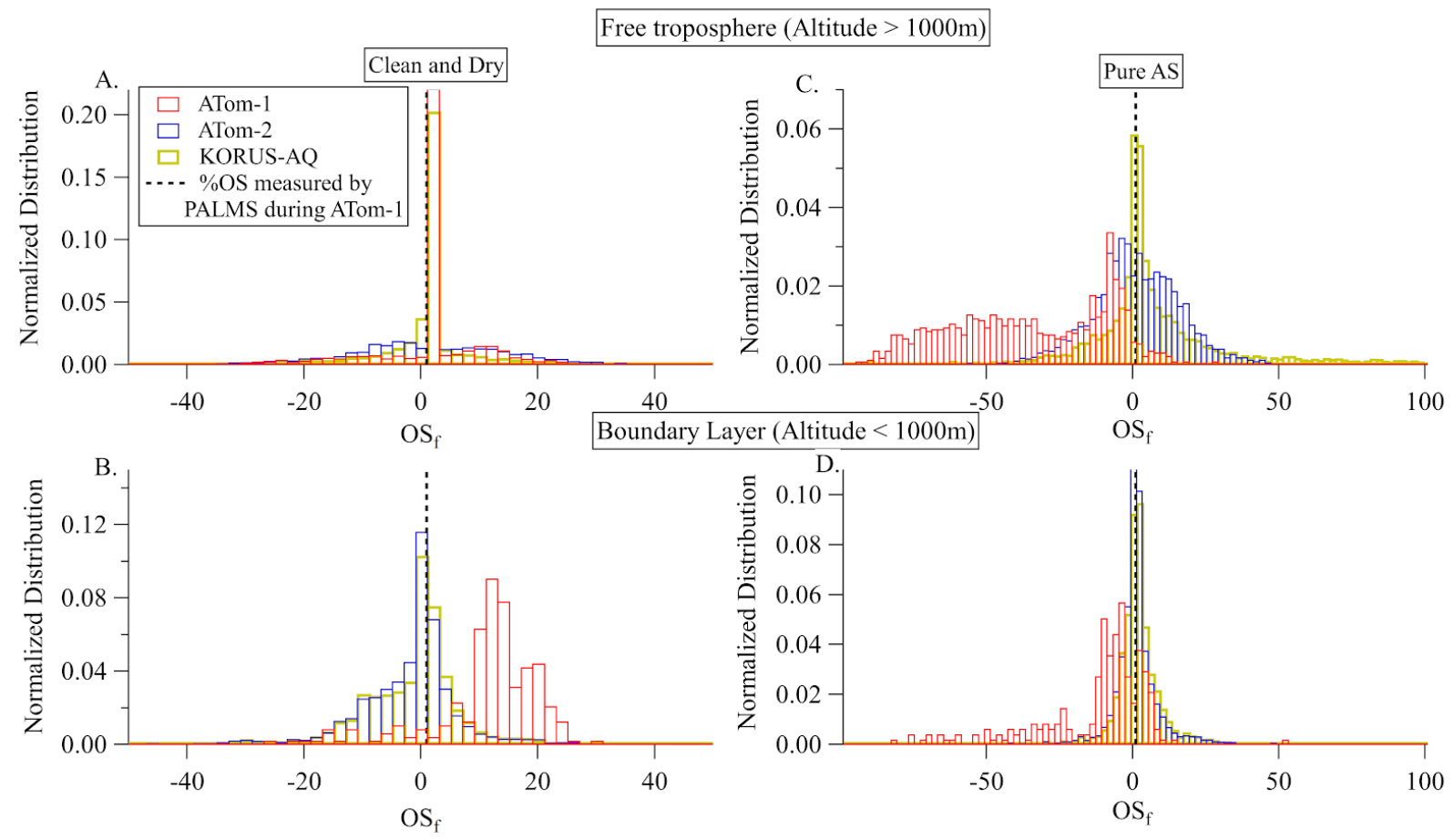

79 Fig. S9. Application of the Song (2019) method for estimating $O S_{f}$ to ATom campaigns and $80 \mathrm{KORUS}$-AQ in regime II (calculated $\left.p H>0, A N_{f}<0.3\right)$ to $(A)$ the free troposphere with "clean and 81 dry" normalization values used, (B) boundary layer with "clean and dry" normalization, $(C)$

82 free troposphere with pure AS calibration values used, and (D) boundary layer with pure AS 83 values used. Dotted line shows the OS\% calculated using data from PALMS during ATom-1. 

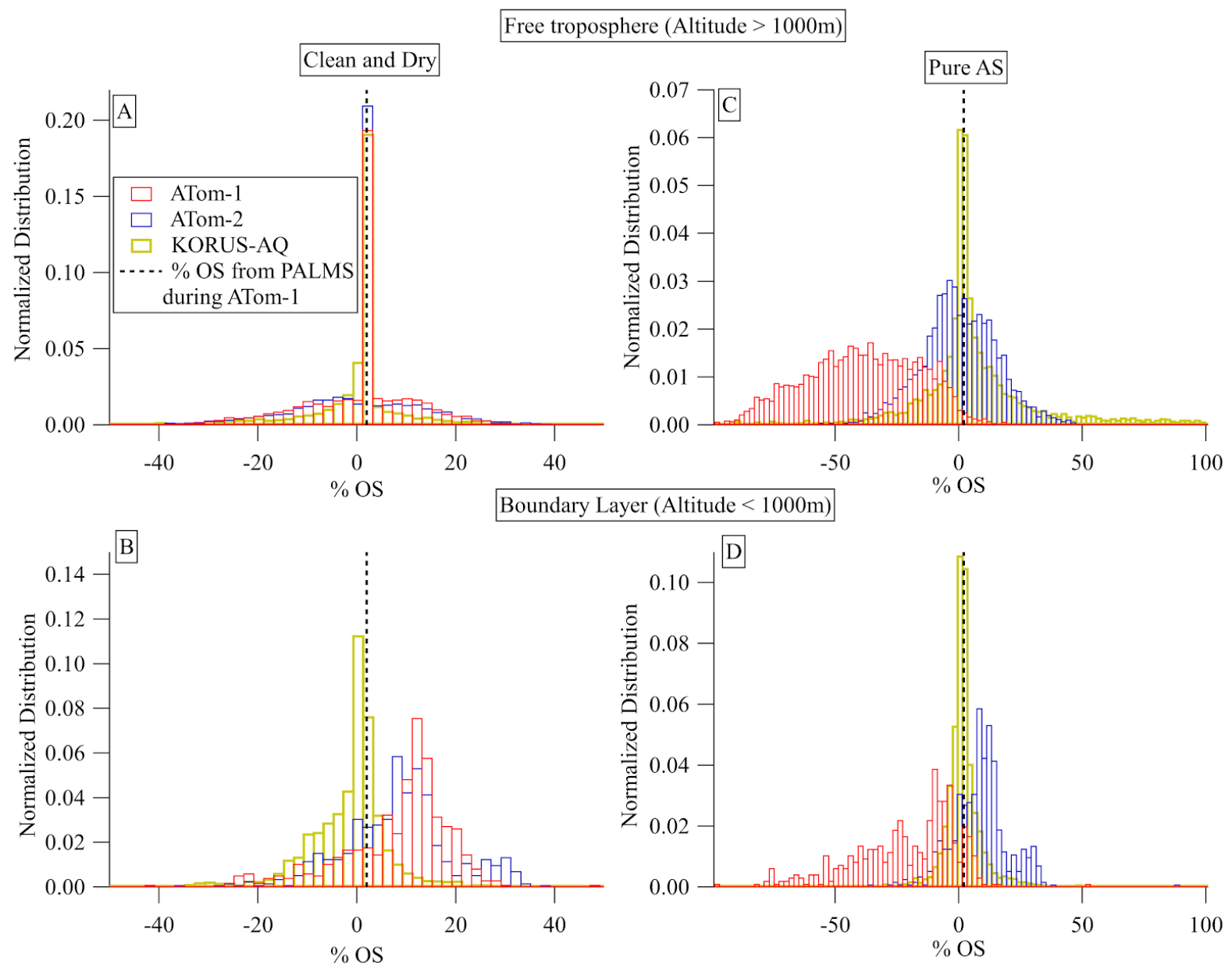

84 Fig. S10. Application of the Song (2019) method for estimating $O S_{f}$ to the entire ATom 85 campaigns and KORUS-AQ to (A) the free troposphere with "clean and dry" normalization 86 values used, (B) boundary layer with "clean and dry" normalization, (C) free troposphere with 87 pure AS calibration values used, and (D) boundary layer with pure AS values used. Dotted line 88 shows the OS\% calculated using data from PALMS during ATom-1. 



89 Fig. S11. Results from GEOS-Chem v12 simulation for the year 2010 for $(A)$ calculated $p H$ at the 90 surface, (B) calculated pH at $400 \mathrm{hPa},(C) A N_{f}$ at the surface, and (D) AN at $400 \mathrm{hPa}$. 


\section{References}

92 Froyd, K. D., Murphy, D. M., Brock, C. A., Campuzano-Jost, P., Dibb, J. E., Jimenez, J.-L.,

93 Kupc, A., Middlebrook, A. M., Schill, G. P., Thornhill, K. L., Williamson, C. J., Wilson, J. C.

94 and Ziemba, L. D.: A new method to quantify mineral dust and other aerosol species from

95 aircraft platforms using single-particle mass spectrometry, Atmospheric Measurement

96 Techniques, 12(11), 6209-6239, doi:10.5194/amt-12-6209-2019, 2019.

97 Song, S., Gao, M., Xu, W., Sun, Y., Worsnop, D. R., Jayne, J. T., Zhang, Y., Zhu, L., Li, M.,

98 Zhou, Z. and Others: Possible heterogeneous chemistry of hydroxymethanesulfonate (HMS) in

99 northern China winter haze, Atmos. Chem. Phys., 19(2), 1357-1371 [online] Available from:

100 https://www.atmos-chem-phys.net/19/1357/2019/acp-19-1357-2019.pdf, 2019. 